\title{
'A dancing ball in the heart': false tendon of the left ventricle simulating a mass lesion
}

\author{
Hashir Kareem, Tom Devasia
}

Department of Cardiology, Kasturba Hospital, Manipal, Karnataka, India

\section{Correspondence to} Dr Hashir Kareem, hashirkareem@gmail.com

\section{DESCRIPTION}

A 44-year-old man presented to us with a history of chest discomfort since 3 days and pain and swelling of the left lower limb. There was no history of dyspnoea, palpitations or syncope. He was a smoker but not a diabetic or hypertensive. Cardiovascular examination was normal. ECG showed inverted T waves in lateral leads. An echocardiogram was performed which showed regional wall motion abnormality in the left anterior descending artery territory with good biventricular function. There was no evidence of pulmonary embolism. A large band-like structure with a fleshy calcific centre was noted in the left ventricular cavity. Troponin T levels were mildly elevated but all other blood investigations were normal. Venous Doppler showed evidence of deep vein thrombosis involving the left lower limb. He was taken up for a coronary angiogram in view of his ECG and echocardiogram findings. The angiogram did not reveal any significant coronary artery disease. However, fluoroscopy of the heart revealed the following interesting finding (videos 1 and 2; figure 1).

A calcific ball-like structure was seen moving in the left ventricular (LV) cavity.

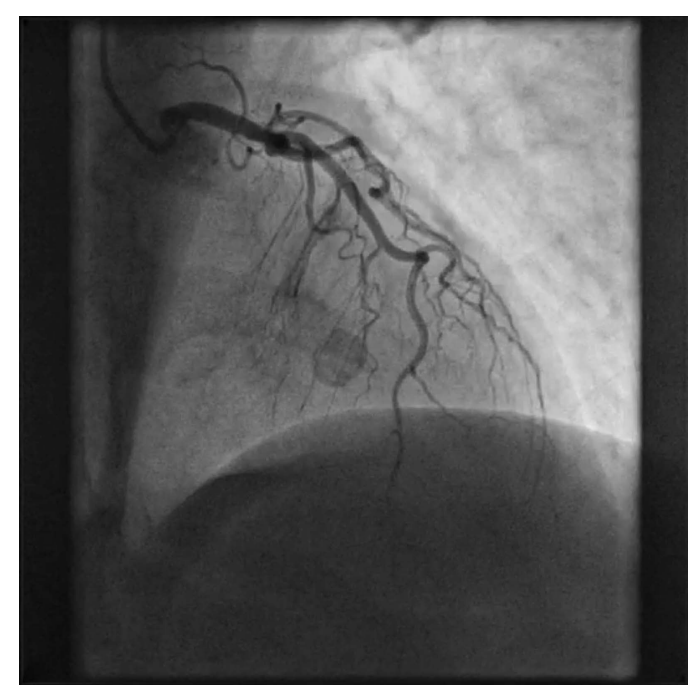

Video 1 Cine angiography image(RAO view) showing the mobile ball like structure in the LV.

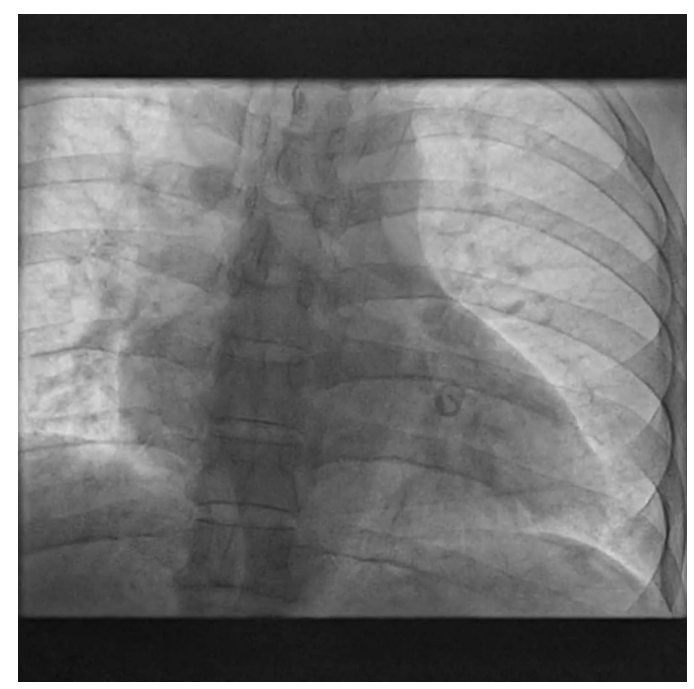

Video 2 Fluoroscopy images (AP view) showing the ball like structure in the LV.

The echocardiogram was repeated. In the midsegment of the LV cavity, a horizontal band (false tendon) was seen with a thick, calcific, ball-like central portion. There were no other mass lesions in the ventricle (video 3; figure 2). The septal and free wall attachments of the band were defined and it was confirmed to be a false tendon. The mass lesion had no direct attachment to any other part of the ventricle. The wall-motion abnormality persisted. There was no evidence of a patent foramen ovale on bubble contrast study.

False tendons are band-like structures sometimes seen in the left ventricle. The incidence varies from $0.4 \%$ to $61 \%$ in various series. ${ }^{1}$ They usually extend from the interventricular septum to the free wall or rarely between two segments of the septum or from the papillary muscle to the septum. They are usually found at the level of the apical or midsegments of the left ventricular cavity. ${ }^{2}$ They are usually thin, band-like structures but they may occasionally be thick and muscular. On the basis of histology, they can be classified into three typesfibrous, fibromuscular and muscular. ${ }^{3}$ The last two types tend to be thicker. False tendons are usually of no clinical significance but their presence may cause diagnostic confusions on the echocardiogram. In this case the false tendon was extremely thick 
Figure 1 Fluoroscopy images showing the calcific mobile ball-like structure in the left ventricle (arrow)
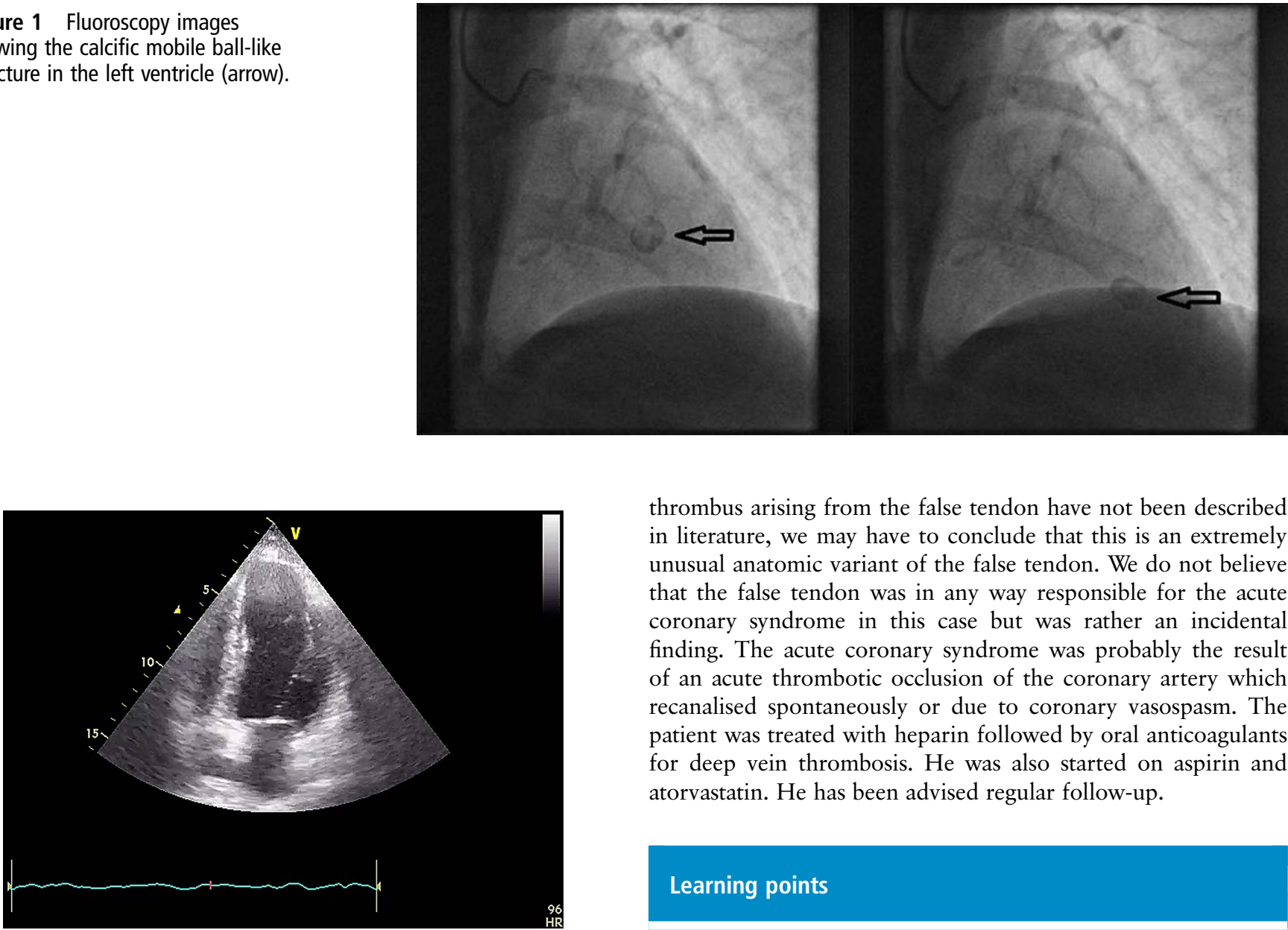

Video 3 Echocardiogram images showing the false tendon with its fleshy, calcified central portion resembling a calcific mass.

and calcified raising the possibility of a mass lesion or thrombus. However, careful echocardiographical assessment revealed the band-like morphology with attachments medially to the septum and laterally to the left ventricular free wall. The interesting fluoroscopy finding was caused by the central ball-like structure on the false tendon which was calcific and hence visible as a freely moving ball during the angiogram. Since tumours or

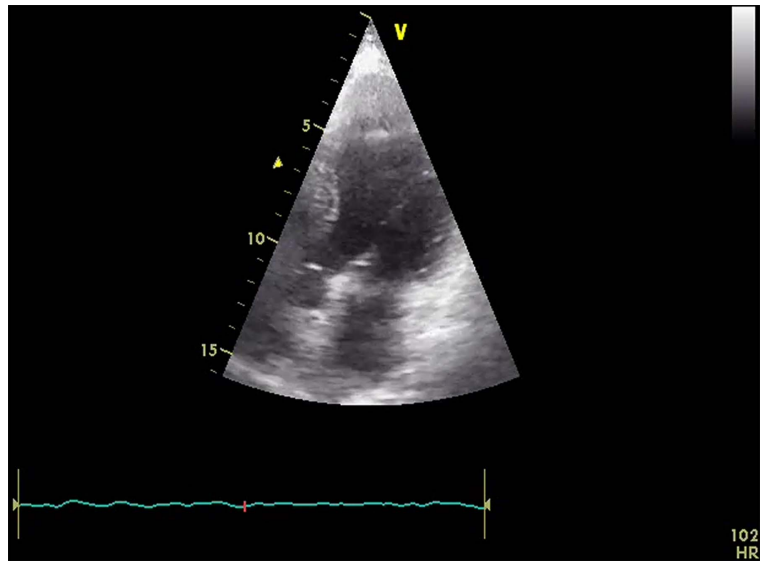

Video 4 Echocardiogram images showing the false tendon with its fleshy, calcified central portion resembling a calcific mass. thrombus arising from the false tendon have not been described in literature, we may have to conclude that this is an extremely unusual anatomic variant of the false tendon. We do not believe that the false tendon was in any way responsible for the acute coronary syndrome in this case but was rather an incidental finding. The acute coronary syndrome was probably the result of an acute thrombotic occlusion of the coronary artery which recanalised spontaneously or due to coronary vasospasm. The patient was treated with heparin followed by oral anticoagulants for deep vein thrombosis. He was also started on aspirin and atorvastatin. He has been advised regular follow-up.

\section{Learning points}

- False tendons are fibromuscular bands seen in the left ventricle.

- Though they are usually thin bands they may occasionally be thick and calcified and may be confused with a mass lesion on echocardiogram or on fluoroscopy.

- Careful assessment of the echocardiogram generally makes the diagnosis evident.

Contributors All authors have participated in the intellectual content and design of this work as well as the writing of the manuscript. HK is the guarantor.

Competing interests None.

Patient consent Obtained.

Provenance and peer review Not commissioned; externally peer reviewed.

\section{REFERENCES}

1 Malouf J, Gharzuddine W, Kutayli F. Reappraisal of the prevalence and clinical importance of left ventricular false tendons in children and adults. $\mathrm{Br}$ Heart $J$ 1986:55:587-91.

2 Leutmer PH, Edwards WD, Seward JB, et al. Incidence and distribution of left ventricular false tendons: an autopsy study of 483 normal human hearts. J Am Coll Cardiol 1986:8:179-83.

3 Philip S, Cherian KM, Wu MC, et al. Left ventricular false tendons: echocardiographic, morphologic and histopathologic studies and review of the literature. Pediatr Neonatol 2011;52:279-86. 

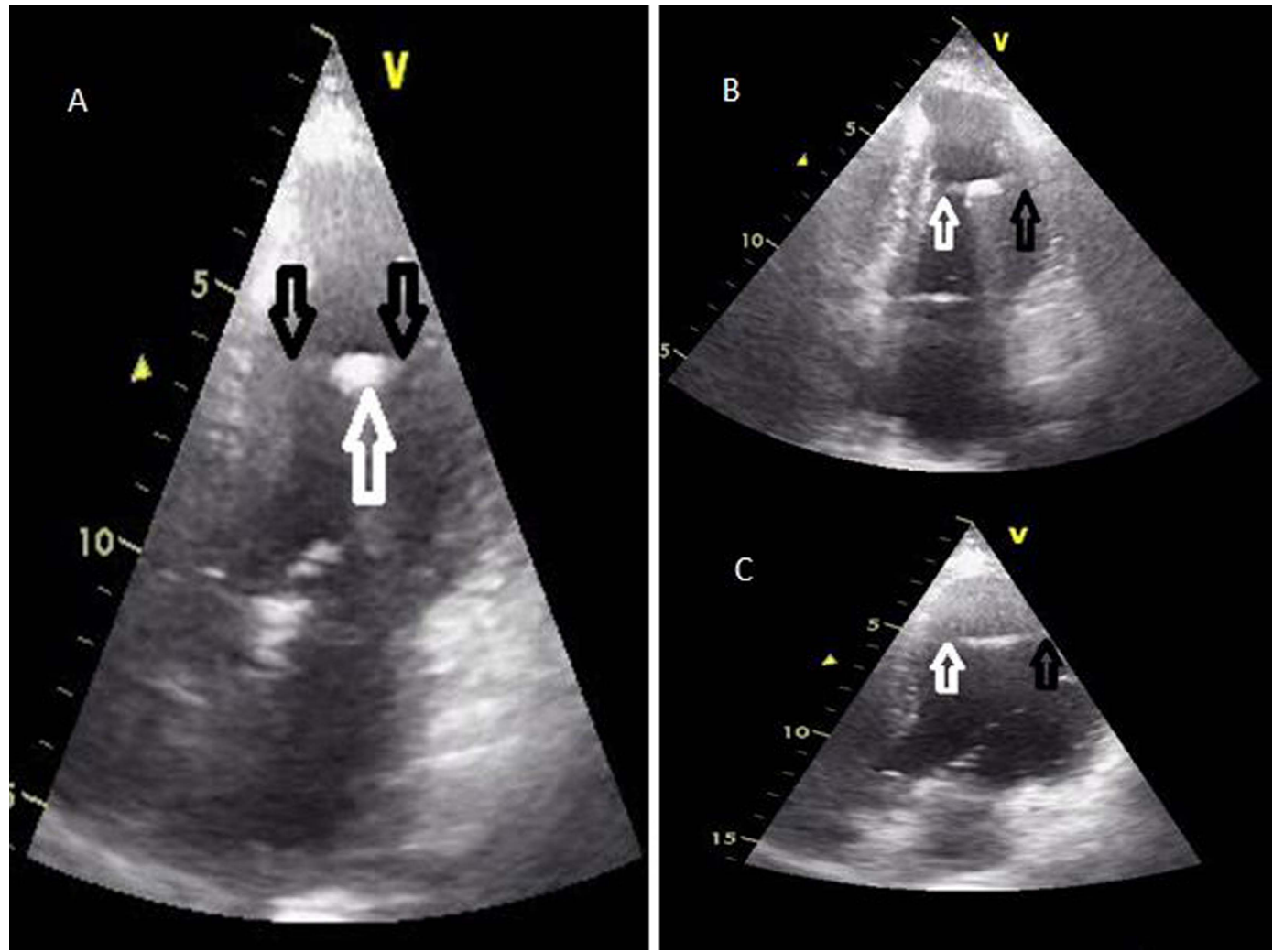

Figure 2 (A) Echocardiogram images showing the attachments of the false tendon (black arrows) and the calcific central part (white arrow) which resembles a mass (B) and (C) showing the medial/septal (white arrow) and lateral/free wall (black arrow) attachments of the false tendon.

Copyright 2013 BMJ Publishing Group. All rights reserved. For permission to reuse any of this content visit

http://group.bmj.com/group/rights-licensing/permissions.

BMJ Case Report Fellows may re-use this article for personal use and teaching without any further permission.

Become a Fellow of BMJ Case Reports today and you can:

- Submit as many cases as you like

- Enjoy fast sympathetic peer review and rapid publication of accepted articles

- Access all the published articles

- Re-use any of the published material for personal use and teaching without further permission

For information on Institutional Fellowships contact consortiasales@bmjgroup.com

Visit casereports.bmj.com for more articles like this and to become a Fellow 